\title{
Are Primary Care Physicians Equipped to Help Persons with Depression? An Exploration of Knowledge, Attitudes and Practices in Kingston, Jamaica RC Gibson ${ }^{1}$, G Walcott ${ }^{2}$
}

\begin{abstract}
Objective: To explore the knowledge, attitudes and practices (KAP) of primary care physicians with regard to depression, as well as the association of personal and professional factors with these parameters.

Method: Through a self-administered questionnaire, all 42 public sector primary care physicians in the Jamaican parishes of Kingston and St. Andrew were surveyed on their demographic characteristics, medical training and career trajectory, as well as on KAP parameters related to depression. Possible associations among the KAP parameters and other variables were explored with non-parametric statistical tests. Statistical significance was taken at $\mathrm{p}<0.05$.

Results: Two-thirds of physicians felt that they were not adequately trained to deal with depression and less than $20 \%$ routinely screened patients with chronic illnesses for depression. Overall, positive attitudes towards persons with depression were prominent. However, negative attitudes towards persons with depression were encountered more commonly among foreign nationals and among persons who had received their medical training overseas $(\mathrm{p}<0.05)$. Physicians earlier in their careers had a greater tendency to view the prescription of antidepressant medications as the exclusive purview of mental health specialists $(\mathrm{p}<0.05)$.

Conclusion: There is scope for further training and sensitization of primary care physicians on issues related to depression. Persons earlier in their careers may benefit from particular emphasis on attitudes towards the management of depression. Foreign nationals and overseas-trained physicians may benefit from particular emphasis on attitudes towards persons with depression.
\end{abstract}

Keywords: Depression, primary care, public health

From: ${ }^{1}$ Department of Community Health \& Psychiatry, University of the West Indies, Mona, Kingston 7, Jamaica. ${ }^{2}$ Kingston \& St. Andrew Public Health Department, Kingston, Jamaica.

Correspondence: Dr Roger Gibson, Department of Community Health and Psychiatry, The University of the West Indies, Mona, Kingston 7, Jamaica. Email: roger.gibson02@uwimona.edu.jm

DOI: $10.7727 /$ wimj.2016.189 


\section{INTRODUCTION}

The high prevalence and morbidity of depression are well documented. For over twenty-five years, epidemiologists have been highlighting the high level of impairment in functioning and well-being that is associated with depressive illnesses $(1,2)$. Globally, depressive disorders were the second largest contributor to years lost to disability in 2013 (3). It has also been projected that by 2030, unipolar depression will become the leading contributor to disease burden worldwide (4).

Despite this knowledge about the extent and impact of depression, many individuals have depressive illnesses that are undetected and untreated $(5,6)$. This has implications for the quality

of life of the individual, societal productivity and preventable economic expenditure (4). In order to bring depression and its negative sequelae under control, existing cases of the condition must be identified and the appropriate treatment initiated. However, there are several potential barriers to both detection and treatment. Detection will be difficult if there is not a certain level of sensitization of the general public that drives appropriate help-seeking behaviour. Another challenge is the possible absence of expertise and skills among the health care professionals who are expected to diagnose and treat the condition.

Data from the World Health Organization (7) indicate that in Jamaica there are 30 psychiatrists serving a population of 2.7 million people. The enormity of the problem of depression demands that in addition to mental health specialists, other physicians also contribute to its detection and management. In many ways the primary care physician is ideally suited for the forefront of the battle against depressive illnesses. Primary care physicians are more likely than any other physicians to be at the point of first contact of an individual with the health services. They therefore tend to have a greater opportunity to detect previously undiagnosed 
illnesses including depression. Primary care physicians also routinely see a number of persons with chronic medical illnesses who often have comorbid depressive illnesses. In Jamaica, Martin et al. (8) found that one third of patients with cardiovascular disease also suffered from depression. Also in Jamaica, Asnani et al. (9) found that one in five patients with sickle cell disease were depressed. These findings attest to the fairly high level of comorbid depression among Jamaicans with chronic illnesses. They also give some indication about the overall prevalence of depression in Jamaica, which would appear to be significant but which can only be estimated because of the absence of any prevalence studies that have targeted the general population.

There have also been no published studies from Jamaica that have assessed the level of preparedness of primary care physicians to contribute to curbing the public health challenge that depression poses. An exploration of this issue may assist with planning appropriate public health initiatives and interventions. In this study, we sought to conduct such an exploration by investigating primary care physicians' knowledge, attitudes and practices (KAP) related to depression, together with possible associated factors such as age, gender, nationality, and medical training and experience.

\section{METHOD}

Ethical approval for conducting this study was obtained from the Ethics Committee of the Ministry of Health. 
A cross-sectional survey of all 42 primary care physicians who were employed in the public health clinics of the Jamaican parishes of Kingston and St. Andrew (KSA) was conducted. Physicians who provided signed, informed consent were asked to anonymously complete a 93item self-administered KAP questionnaire. The instrument had originally been developed for use in the Bahamas by a colleague who made it available to the researchers of the current study for modification and use. Minor adjustments were made to ensure that the wording was appropriate for the Jamaican context. The questionnaire consisted of a mixture of open-ended, "Yes/ No", and Likert type items. The instrument was designed to obtain information on participants' sociodemographic characteristics; their training and experience; and their knowledge, attitudes and practice pertaining to depressive illnesses. The following are some examples of questions from the relevant areas of the questionnaire:

Sociodemographic characteristics

What is your age?

What is your country of birth?

Training and experience

In what year did you graduate from medical school?

In what country did you complete your medical degree?

Knowledge about depressive illnesses

From the list of medications below please indicate which pharmaceutical agents can be utilized as first line treatment in the management of depression.

[Response options provided were: yes, no, and unsure].

Chlorpromazine

Amitriptylene 


\section{Paroxetine}

Which of the following are diagnostic symptoms for depression in adults?

[Response options provided were: yes, no, and unsure].

Symptoms must be present for at least two weeks

Memory loss

Unreasonable guilt

Attitudes towards depressive illnesses

Please answer each item by ticking the appropriate response.

[Response options provided were: strongly disagree, disagree, neither agree nor disagree, agree, and strongly agree].

$\cdots$

I don't believe that primary care physicians should be expected to diagnose and treat depressive disorders

Practice issues related to depressive illnesses

Please answer each item by ticking the appropriate response.

[Response options provided were: never, rarely, infrequently, often, always/ routinely].

I undertake screening for depression on all patients whom I treat at the clinic. 
For the purpose of this paper, the authors focused on the variables of interest outlined below. Their selection was based on the authors' independent assessment and subsequent consensus on the questionnaire items that were best aligned to their objectives.

The demographic and training variables that were selected for analysis were age, gender, years since graduation from medical school, country of birth, and country of medical degree. Because of low cell counts in some categories of the "country of birth" and "country of medical degree" variables, both were collapsed into dichotomous variables with the new categories being "Jamaica" and "other."

Knowledge was assessed by obtaining scores that were derived from participants' responses to a series of "Yes/ No/ Unsure" questions about medication used in the treatment of depression as well as their responses to another series of "Yes/ No/ Unsure" questions that inquired about the criteria used to diagnose the condition. Each correct response was awarded one point; there were no penalties for incorrect answers or for responses of "unsure." The possible ranges of scores were 0 to 9 for the set of questions about medication (management score) and 0 to 17 for the set of questions related to diagnosis (diagnosis score).

The attitudinal variables selected for analysis were: the perception of adequacy of training, the perception of depression as a manifestation of weakness, the pointlessness (or value) of screening for depression, openness to discussing suicide with patients, confidence with treating uncomplicated depression, and attitude towards prescribing antidepressants.

The variables related to physicians' clinical practice that were included in the analysis were those that captured the extent to which they: screened all patients, screened chronically ill patients, used screening tools and accessed specialist advice. 
All analyses were conducted using the Statistical Package for the Social Sciences (SPSS; version 12). Frequencies, medians and interquartile ranges were calculated as appropriate. Possible associations between variables were explored with various statistical tests. Spearman's test for correlation was conducted when the variables were a combination of two continuous variables, e.g. age and diagnosis score. The Mann-Whitney U test was conducted when the variables were a combination of a dichotomous categorical variable and a continuous variable, e.g. Country of training (Jamaica/ other) and management score. The Kruskal Wallis test was conducted when the variables were a combination of a non-dichotomous categorical variable and a continuous variable, e.g. perceived adequacy of training (5 categories) and age. Fisher's Exact test was conducted when the variables were a combination of two categorical variables, e.g. perception of adequacy of training and country of training.

In all analyses, statistical significance was taken at $\mathrm{p}<0.05$.

\section{RESULTS}

All forty-two eligible participants completed the survey. The majority (76\%) were female and they ranged in age from 23 to 63 years with a median age of 29 years [interquartile range (IQR) $=12]$. The median duration of time since graduation from medical school was 3.5 years (IQR $=$

10.25 ; range $=1-37$ years $)$. Just under three quarters $(72.5 \%)$ of participants were Jamaican with a similar proportion (76.2\%) having received undergraduate medical training in Jamaica (Table 1). 
Participants' scores on knowledge about the pharmacological management of depression ranged from 0 to 9 with the median score being six (6) and the IQR five (5). Their scores on knowledge about the diagnosis of depression ranged from seven (7) to fifteen (15) with a median of eleven (11) and IQR of three (3) (Table 1).

The frequency of endorsement of the various Likert and "yes/ no" categories of the attitude and practice items of interest are also illustrated in Table 1. Of note, about two thirds of the respondents felt that they were not adequately trained to deal with depression $(54.8 \%$ agreed and $11.9 \%$ strongly agreed), and only $40.5 \%$ felt confident with treating patients with uncomplicated depression. On the other hand, the vast majority of respondents believed that screening for depression was not pointless (95.2\%), were open to discussing suicide with patients (95.2\%) and disagreed (35.7\% disagreed; 59.5\% strongly disagreed) that depression was a manifestation of weakness. Most physicians also disagreed (40.5\% disagreed; $16.7 \%$ strongly disagreed) that antidepressants should only be prescribed by mental health professionals.

With regard to practice issues, although most physicians disagreed that screening was pointless, only $16.7 \%$ often screened all patients and only $17.6 \%$ often or always screened chronically ill patients in particular. On the other hand, specialist mental health services were rated as being accessible by over two thirds (70.7\%) of physicians.

Table 2 illustrates the findings of various tests of association between knowledge, attitude and practice variables and: age, gender, years since graduation from medical school, country of birth and country of undergraduate medical training. By and large, no significant associations were found. However, there were some notable exceptions. Firstly, there was an association between the number of years since graduation and the attitude that antidepressant medications 
should only be prescribed by mental health professionals. Persons who strongly disagreed with this attitude had a median duration of time since graduation of ten $(10)$ years $(\mathrm{IQR}=15)$, compared with a median duration of 6.5 years $(\mathrm{IQR}=9)$ among persons who strongly agreed $(\mathrm{p}<$ $0.05)$.

There was also an association between country of birth and the attitude of regarding depression as a manifestation of weakness. This attitude was encountered in $18.2 \%$ of nonJamaicans but was not found in any of the Jamaican participants $(p<0.05)$. The country of undergraduate medical training showed a similar association with the attitude of regarding depression as a manifestation of weakness. Whereas none of the participants with Jamaican medical degrees endorsed this view, it was endorsed by $20 \%$ of persons who had obtained medical degrees in other countries $(\mathrm{p}<0.05)$.

\section{DISCUSSION}

The enormity of the problem with depressive illnesses means that the patient load cannot be sustained by these relatively few psychiatrists. Primary care physicians are much greater in number and in reach, e.g. forty-two were operating in the two (out of a total of fourteen) parishes that were the subject of this survey, as opposed to the 30 psychiatrists serving the entire country (7). The more diffuse network of primary care physicians is a potentially important resource for the detection and management of depression. It is therefore troubling that most primary care physicians surveyed (66.7\%) felt that their training had not prepared them for these tasks or failed to endorse feelings of confidence (21.4\% were not confident; $33.3 \%$ were unsure) about their ability to manage uncomplicated depression. These findings are strongly suggestive of a 
need to retrain physicians already involved in primary care in the diagnosis and management of depression as well as to bolster the existing training offered in medical school in Jamaica.

Encouragingly, the basic attitudes towards depression appear to be positive (e.g. 95.2\% rejection of the view that depression is a manifestation of weakness) and current knowledge scores were fair. This suggests that there is a solid foundation on which further training may be established. The resources that are needed for this training are also likely to be fewer than if basic knowledge and attitudes had been poor. This is an important consideration in resourcepoor settings and should give hope to proponents and financers of training that much can be achieved with modest investment. At the same time, the findings suggest that persons with nonJamaican nationality or training may require some additional attention to basic attitudes besides the training being suggested for all primary care physicians.

One potential challenge to the mounting of successful further training of primary care physicians (and possibly medical students) is the commonly (31\%) held attitude that the prescription of antidepressant medications is the exclusive purview of mental health specialists. As previously noted, this attitude was more commonly found among more recent graduates of medical school. This observation may reflect an increasing dependence on mental health specialists with the passage of time. Such a dependence is likely to have been fostered by the increase in the number of psychiatrists and other mental health specialists that has occurred with the establishment of the postgraduate training programme in Psychiatry at the University of the West Indies, Mona, Jamaica in 1965 (10) and with the general expansion of the country's mental health services (11). With the advent of increasing numbers of specialists the perceived need for primary care physicians to engage in the detection and management of mental health conditions like depression may have diminished. However, the gravity of the public health problem posed 
by depression demands that the extensive network of primary care physicians return to a central role in the detection and management of this condition.

Notwithstanding the arguments in favour of strengthening the contribution of primary care physicians to the management of depression, the role of mental health specialists remains critical. For example, their expertise may be beneficial in dealing with complex cases. In fact, with the expansion of primary care physicians' skills and competencies to manage depression, the roles of the primary care physician and the mental health specialist should ideally complement each other. Primary care physicians who are able to detect cases of depression and manage persons with uncomplicated presentations may refer to specialists persons whose depression is complicated or resistant to treatment. In this way, the efficiency, reach and comprehensiveness of mental health services for persons with depression may be significantly enhanced. In this regard, it is reassuring to note that the vast majority of primary care physicians who were surveyed $(70.7 \%)$ reported that mental health specialists were accessible to them; thus the fundamentals of a collaborative approach may already be in place.

In summary, depression is a significant public health problem, the tackling of which requires the input of primary care physicians. This study indicates that primary care physicians require more training and sensitization in order to effectively deal with this public health challenge in collaboration with mental health specialists.

\section{Limitations}

Not all physicians who work in primary care settings in Jamaica were represented in this study. A number of other physicians work in public health clinics in other parishes of Jamaica as well as in private practice. It is therefore possible that the findings do not reflect what obtains In Jamaica as a whole. 


\section{ACKNOWLEDGEMENT}

We wish to acknowledge the input of Dr. Nelson Clarke from the University of the West Indies

School of Clinical Medicine in the Bahamas. He generously made available for modification and incorporation into the current study a questionnaire which he had developed for his own research. 


\section{REFERENCES}

1. Wells KB, Stewart A, Hays RD, Burnam MA, Rogers W, Daniels M et al. The functioning and well-being of depressed patients: results from medical outcomes study. J Am Med Assoc 1989; 262: 914-919.

2. Broadhead WE, Blazer DG, George LK, Tse CK. Depression, disability days, and days lost from work in a prospective epidemiologic survey. J Am Med Assoc 1990; 264: 25242528.

3. Global Burden of Disease Study 2013 Collaborators. Global, regional, and national incidence, prevalence, and years lived with disability for 301 acute and chronic diseases and injuries in 188 countries, 1990-2013: a systematic analysis for the Global Burden of Disease Study 2013. Lancet 2015; 386: 743-800.

4. Lépine JP, Briley M. The increasing burden of depression. Neuropsychiatr Dis Treat 2011; 7(Suppl 1):3-7.

5. Poulsen KM, Pachana NA, McDermott BM. Health professionals' detection of depression and anxiety in their patients with diabetes: The influence of patient, illness and psychological factors. J Health Psychol $2014 \quad$ Dec 14. doi:10.1177/1359105314559618. [Epub ahead of print]

6. Alvarado R, Rojas G. Evaluation of the program for detection and treatment of depression in Chilean primary care centers. Rev Med Chil 2011; 139: 592-599.

7. World Health Organization. WHO-AIMS Report on Mental Health System in Jamaica. Kingston, Jamaica: World Health Organization and Ministry of Health Jamaica; 2009. 
8. Martin JS, Neita SM, Gibson RC. Depression among cardiovascular disease patients on a consultation- liaison service at a general hospital in Jamaica. West Indian Med J 2012; 61: 499-503.

9. Asnani MR, Fraser R, Lewis NA, Reid M. Depression and loneliness in Jamaicans with sickle cell disease. BMC Psychiatry. 2010 Jun 7. doi: 10.1186/1471-244X-10-40.

10. Hickling FW, Gibson RC. The history of Caribbean psychiatry. In: Hickling FW, Sorel E, eds. Images of Psychiatry: The Caribbean. Kingston: University of the West Indies; 2005: $15-41$.

11. Abel W, McCallum M, Hickling FW, Gibson RC. Mental health services and public policy in Jamaica. The history of Caribbean psychiatry. In: Hickling FW, Sorel E, eds. Images of Psychiatry: The Caribbean. Kingston: University of the West Indies; 2005: 297-313. 
Table 1. Sociodemographic and training characteristics of physicians and their knowledge, attitudes and practices pertaining to depressive illnesses

\begin{tabular}{|c|c|c|}
\hline Variable & $\begin{array}{l}\text { Frequencies n (\%), medians, interquartile ranges and } \\
\text { ranges }^{1,2}\end{array}$ & $\begin{array}{l}\text { Number of } \\
\text { physicians } \\
\text { with } \\
\text { missing } \\
\text { data }\end{array}$ \\
\hline \multicolumn{3}{|l|}{$\begin{array}{l}\text { Sociodemographic and } \\
\text { training characteristics: }\end{array}$} \\
\hline Age (years) & Median: 29; IQR: 12; Range: 23- 63 & 2 \\
\hline Time since graduation (years) & Median: 3.5; IQR: 10.25; Range:1-37 & 0 \\
\hline Gender & $32(76 \%) \mathrm{F} ; 10(24 \%) \mathrm{M}$ & 0 \\
\hline Country of birth & 29 (72.5) Jamaican; 11 (27.5) other & 2 \\
\hline Country of degree & 32 (76.2) Jamaican; 10 (23.8) other & 0 \\
\hline \multicolumn{3}{|l|}{ Knowledge: } \\
\hline Diagnosis score $^{3}$ & Median: 11; IQR: 3; Range: 7-15 & 0 \\
\hline Management score ${ }^{4}$ & Median: 6; IQR: 5; Range: 0-9 & 0 \\
\hline \multicolumn{3}{|l|}{ Attitude: } \\
\hline Not adequately trained & SD 2 (4.9); D 8 (19.5); NAD 3 (7.1); A 23 (54.8); SA 5 (11.9) & 1 \\
\hline Depression as weakness & SD 25 (59.5); D 15 (37.5); NAD 0 (0); A 2 (4.8); SA 0 (0) & 0 \\
\hline $\begin{array}{l}\text { Antidepressants should only be } \\
\text { prescribed by specialists }\end{array}$ & SD 7 (16.7); D 17 (40.5); NAD 5 (11.9); A 11 (26.2); SA 2 (4.8) & 0 \\
\hline Pointless to screen & No 40 (95.2); Yes 1 (2.4); Not sure 1 (2.4) & 0 \\
\hline Open to discussing suicide & No 1 (2.4); Yes 40 (95.2); Not sure 1 (2.4) & 0 \\
\hline $\begin{array}{l}\text { Confidence with treatment of } \\
\text { uncomplicated depression }\end{array}$ & No 9 (21.4); Yes 17 (40.5); Not sure 14 (33.3) & 2 \\
\hline \multicolumn{3}{|l|}{ Practice: } \\
\hline Screen all patients & $\begin{array}{l}\text { Nev } 13 \text { (31.0); R } 11 \text { (26.2); Infreq } 11 \text { (26.2); Often } 7 \text { (16.7); } \\
\text { Always } 0(0)\end{array}$ & 0 \\
\hline Screen chronically ill patients & $\begin{array}{l}\text { Nev } 6 \text { (14.3); R } 19 \text { (45.2); Infreq } 10 \text { (23.8); Oft } 3 \text { (7.1); } \\
\text { Always } 4 \text { (9.5) }\end{array}$ & 0 \\
\hline Use screening tools & $\begin{array}{l}\text { Nev } 11 \text { (26.2); R } 4 \text { (9.5); Infreq } 13 \text { (31.0); Oft } 9 \text { (21.4); } \\
\text { Always } 4 \text { (9.5) }\end{array}$ & 1 \\
\hline Access to specialist advice & No 9 (22.0); Yes 29 (70.7); Not sure 3 (7.3) & 1 \\
\hline
\end{tabular}


Table 2. Statistical tests of association between knowledge, attitude and practice issues regarding depressive illnesses among primary care physicians and: sociodemographic characteristics, country of birth and country of medical training.

\begin{tabular}{|c|c|c|c|c|c|}
\hline & \multicolumn{5}{|c|}{ p-values } \\
\hline & Age & Gender & $\begin{array}{l}\text { Years since } \\
\text { graduation }\end{array}$ & $\begin{array}{l}\text { Country of } \\
\text { birth }\end{array}$ & $\begin{array}{l}\text { Country of } \\
\text { training }\end{array}$ \\
\hline \multicolumn{6}{|l|}{ Knowledge: } \\
\hline Diagnosis score & $0.60^{1}$ & $0.64^{2}$ & $0.23^{1}$ & $0.74^{2}$ & $0.07^{2}$ \\
\hline $\begin{array}{l}\text { Management } \\
\text { score }\end{array}$ & $0.21^{1}$ & $0.93^{2}$ & $0.41^{1}$ & $0.25^{2}$ & $0.43^{2}$ \\
\hline \multicolumn{6}{|l|}{ Attitude: } \\
\hline $\begin{array}{l}\text { Not adequately } \\
\text { trained }\end{array}$ & $0.76^{3}$ & $0.59^{4}$ & $0.86^{3}$ & $0.17^{4}$ & $0.10^{4}$ \\
\hline $\begin{array}{l}\text { Depression as } \\
\text { weakness }\end{array}$ & $0.21^{3}$ & $0.69^{4}$ & $0.26^{3}$ & $0.03^{4 *}$ & $0.04^{4 *}$ \\
\hline $\begin{array}{l}\text { Pointless to } \\
\text { screen }\end{array}$ & $0.67^{3}$ & $1.00^{4}$ & $0.55^{3}$ & $0.07^{4}$ & $0.05^{4}$ \\
\hline $\begin{array}{l}\text { Open to } \\
\text { discussing } \\
\text { suicide }\end{array}$ & $0.37^{3}$ & $0.42^{4}$ & $0.30^{3}$ & $0.07^{4}$ & $0.05^{4}$ \\
\hline $\begin{array}{l}\text { Confidence } \\
\text { with treatment } \\
\text { of } \\
\text { uncomplicated } \\
\text { depression }\end{array}$ & $0.21^{3}$ & $0.65^{4}$ & $0.44^{3}$ & $0.40^{4}$ & $0.23^{4}$ \\
\hline $\begin{array}{l}\text { Antidepressants } \\
\text { should only be } \\
\text { prescribed by } \\
\text { specialists }\end{array}$ & $0.06^{3}$ & $1.00^{4}$ & $0.03^{3 *}$ & $0.30^{4}$ & $0.50^{4}$ \\
\hline \multicolumn{6}{|l|}{ Practice: } \\
\hline $\begin{array}{l}\text { Screen all } \\
\text { patients }\end{array}$ & $0.21^{3}$ & $0.70^{4}$ & $0.42^{3}$ & $1.00^{4}$ & $0.35^{4}$ \\
\hline $\begin{array}{l}\text { Screen } \\
\text { chronically ill } \\
\text { patients }\end{array}$ & $0.22^{3}$ & $0.33^{4}$ & $0.27^{3}$ & $0.48^{4}$ & $0.08^{4}$ \\
\hline $\begin{array}{l}\text { Use screening } \\
\text { tools }\end{array}$ & $0.75^{3}$ & $0.79^{4}$ & $0.71^{3}$ & $0.12^{4}$ & $0.79^{4}$ \\
\hline $\begin{array}{l}\text { Access to } \\
\text { specialist } \\
\text { advice }\end{array}$ & $0.42^{3}$ & $0.69^{4}$ & $0.11^{3}$ & $0.61^{4}$ & $0.85^{4}$ \\
\hline
\end{tabular}

